\title{
Predictive factors for survival of patients with inoperable malignant distal biliary strictures: a practical management guideline
}

\author{
F Prat, O Chapat, B Ducot, T Ponchon, J Fritsch, A D Choury, G Pelletier, C Buffet
}

\begin{abstract}
Background-Stenting is the treatment of choice for inoperable malignant strictures of the common bile duct. Criteria for the choice of stents (plastic versus metallic) remain controversial because predicting survival is difficult.

Aims-To define prognostic factors in order to improve the cost effectiveness of endoscopic palliation.

Patients-One hundred and one patients were included in a prospective trial. Seven prognostic variables for survival were analysed (age, sex, bilirubinaemia, weight loss, presence of liver metastases, and tumour histology and size). All patients were followed until death or at least one year after inclusion. By the end of the study, $81(80.2 \%)$ patients had died.

Results-In univariate analysis, the variables associated with survival were weight loss $(p<0.05)$ and tumour size $(p<0.01)$. By multivariate analysis, tumour size was the only independent prognostic factor $(p<0.05)$. A threshold of $30 \mathrm{~mm}$ at diagnosis distinguished two survival profiles: the median survival of patients with a tumour greater than $30 \mathrm{~mm}$ was 3.2 months, whereas it was 6.6 months for patients with a tumour less than $30 \mathrm{~mm}(\mathbf{p}<0.001)$. Conclusions-A practical strategy could be based on tumour size at diagnosis: a metal stent should be systematically chosen for patients with an inoperable tumour smaller than $30 \mathrm{~mm}$, while larger tumours are efficiently palliated by a plastic stent.
\end{abstract}

(Gut 1998;42:76-80)

Keywords: stents; pancreatic cancer; endoscopic retrograde cholangiopancreatography; prognostic factors; biliary tract cancer; palliative treatment

Approximately $10-20 \%$ of patients with malignant obstruction of the common bile duct are nowadays operated on with the intention of complete resection and cure. Half of these patients will undergo resection, and the others some form of palliative bypass surgery. ${ }^{12}$ Ninety per cent of patients with malignant obstructive jaundice may therefore benefit only from palliative treatment. Among these patients, some will survive only a few weeks, most will die within six months, but some others may survive in a fairly good condition for one or even several years. ${ }^{3}$ Until recently, two kinds of therapeutic options were offered to such patients: a surgical bypass or an endoprosthesis, generally made of polyethylene. The percutaneous insertion of plastic endoprostheses has been shown to generate excess morbidity ${ }^{4}$ due to a 12 French gauge access through the liver; however, even with the use of thinner catheters (7 French) and self expanding stents, the transhepatic route remains more invasive than the endoscopic route, and should not be the primary option for common bile duct obstruction, although it can be recommended for the palliation of hilar strictures.

Several studies have shown the advantages of endoscopic stenting over surgical bypass, although "long term survivors" could clearly benefit from palliative surgery by precluding the need for stent exchanges necessitated by stent clogging. ${ }^{5-7}$ The recent introduction of self expanding metal stents, whose patency has been shown to be longer than that of plastic stents, may affect the decision: endoscopic stenting could be the option of choice for all patients unlikely to undergo curative resection. ${ }^{8}{ }^{9}$ However, economic issues must be considered, and metallic stents, due to their high cost, should probably be reserved for those patients whom they might really benefit. ${ }^{10}$ Prediction of survival therefore becomes a critical issue, but reliable predictive factors are still lacking. Because life expectancy can be an essential determinant in a patient's management, we tried in this study to identify prognostic indicators and to suggest a simple management guideline.

\section{Methods and patients}

The present study is derived from a prospective randomised trial aimed at comparing three methods of endoscopic drainage for inoperable malignant strictures of the common bile duct. The results of this trial have been reported elsewhere. ${ }^{11}$

Criteria for inclusion were: existence of jaundice secondary to a distal malignant common bile duct stricture, without previous attempts at biliary drainage; referral to one of the two participant centres (Bicêtre Hospital or Edouard Herriot Hospital) for endoscopic palliation of jaundice; performance status of 0 (asymptomatic), 1 (symptomatic, fully ambulatory), or 2 (symptomatic, in bed less than $50 \%$ of day) after the Eastern Cooperative Oncology Group (ECOG) classification ${ }^{12}$ and ASA grade 1 or $2^{13}$; or a decision that the patient was unfit for surgery on the basis of tumour extension (estimated by clinical
Dr Prat.

Accepted for publication 24 June 1997 
Table 1 Patient characteristics

\begin{tabular}{|c|c|}
\hline No of patients & 101 \\
\hline Mean (SD) age (y) & $73.2(12.5)$ \\
\hline Age range $(y)$ & $39-95$ \\
\hline $\operatorname{Sex}(M / F)$ & $49 / 52$ \\
\hline \multicolumn{2}{|l|}{ Percentage weight loss } \\
\hline Mean (SD) & $9.1(6.9)$ \\
\hline Range & $0-27$ \\
\hline \multicolumn{2}{|l|}{ Diagnosis $(\%)$} \\
\hline Cancer of the pancreatic head & $65(64.3)$ \\
\hline Cholangiocarcinoma & $21(20.8)$ \\
\hline Ampullary cancer & $3(3.0)$ \\
\hline Metastatic lymph nodes & $12(11.9)$ \\
\hline \multicolumn{2}{|l|}{ Tumour size in $\mathrm{mm}$} \\
\hline Mean (SD) & $33.8(13.9)$ \\
\hline Median & 30 \\
\hline Range & $(10-80)$ \\
\hline No of patients with liver metastases (\%) & $28(27.7)$ \\
\hline $\begin{array}{l}\text { Mean (SD) bilirubinaemia before first stent } \\
\text { (normal }<17 \mu \mathrm{mol} / \mathrm{l})\end{array}$ & $248.7(163.8)$ \\
\hline
\end{tabular}

examination, chest $x$ ray, transcutaneous abdominal ultrasonography and/or computed tomography scan, and endoscopic ultrasonography in some cases), or age. Exclusion criteria were: the patient's residence located abroad or more than $150 \mathrm{~km}$ (100 miles) from the endoscopy centre; an extension of the stricture to the main biliary confluence (hilum) or the existence of obstructive duodenal invasion; a suspected benign biliary stricture; or the patient's refusal to participate after receiving information about the trial. The study was approved by the ethics committee of the Lyon Civil Hospitals, and patients were included after written informed consent was obtained.

At inclusion, patient characteristics were noted on a specific form and then entered onto a database. Patients were followed prospectively by monthly mailings and telephone calls to the referring centres and general practitioners. Follow up was conducted until the patient's death or for at least one year after inclusion. The global survival was defined as the timespan between initial stenting and death.

Of the patient data, seven criteria were considered for the prognostic study, with regard to the following criteria: previously reported or studied in the literature as potentially related to survival of patients with pancreaticobiliary cancers; and usual availability of data in the common set of clinical, biological, and morphological investigations. Data such as a thorough assessment of nutritional status were therefore not considered; neither was the performance status, since all the patients were classified as

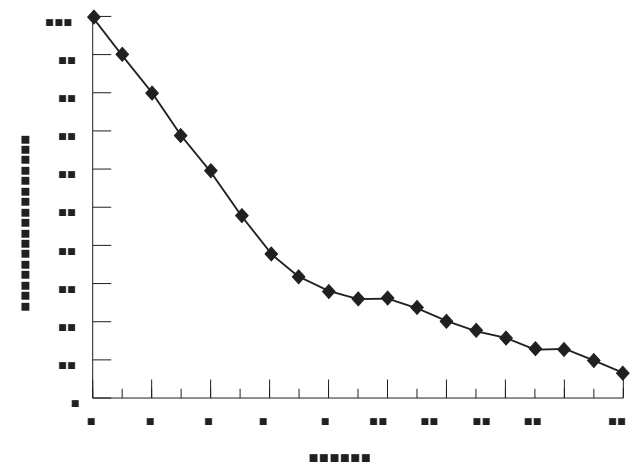

Figure 1 Global survival curve.
Table 2 Prognostic significance for survival of commonly available criteria at the time of diagnosis (log rank test and Cox model)

\begin{tabular}{llll}
\hline Variable studied & $\begin{array}{l}\text { Relative } \\
\text { risk }\end{array}$ & $95 \%$ CI & p Value \\
\hline Univariate analysis & NA & NA & NS \\
Age & NA & NA & NS \\
Bilirubinaemia & NA & NA & NS \\
Liver metastases & NA & NA & p $<0.05$ \\
Percentage weight loss & NA & NA & NS \\
Sex & NA & NA & p $<0.01$ \\
Tumour size & NA & NA & NS \\
Type of primary tumour & & & \\
Multivariate analysis & NA & NA & NS \\
Weight loss & 1 & NA & NA \\
Tumour size $<30 \mathrm{~mm}$ & 2.5 & $1.4-4.3$ & p<0.01 \\
Tumour size $\geqslant 30 \mathrm{~mm}$ & & & \\
\hline
\end{tabular}

ECOG 2 or less. The seven items were the patient's age, sex, and weight loss, the tumour size and histological type, the presence or absence of distant metastases (to the liver), and total serum bilirubin the day before stenting. Percentage weight loss was calculated by the formula: 1-(weight on inclusion/usual weight). Tumour size was defined as the largest diameter when a mass was visible on transcutaneous ultrasound or computed tomography scan (the images available at the time of endoscopic retrograde cholangiopancreatography (ERCP) were usually from the peripheral hospital referring the patient), and as the total length of the stricture on retrograde cholangiography when no mass was identifiable. In patients with a visible mass, it was checked that mass diameter and stricture length on ERCP were correctly correlated. Histology was classified as pancreatic head carcinoma, cholangiocarcinoma, ampullary carcinoma, and metastatic lymph nodes; it was obtained from guided needle biopsies, biliary brush cytology and biopsies, or from knowledge of the primary tumour. When no histological sample was available, morphological criteria such as a double stricture of the common bile and pancreatic ducts for a pancreatic head carcinoma, were accepted.

Randomisation was done in blocks of six patients each stratified for both sex and investigation centre. The three randomisation groups were mixed for the prognostic study because their global survivals were not different. ${ }^{11}$ Furthermore, the comparability of the three groups for the different patient variables was tested. In a second step, univariate and multivariate analyses of the different factors were undertaken. Finally, the prognostic factors were tested in the study population.

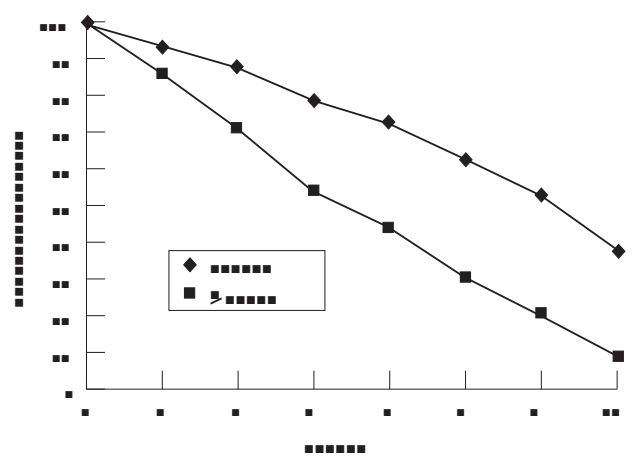

Figure 2 Survival curves for small and large tumours. 
Table 3 Classification of patients according to tumour size and survival

\begin{tabular}{lll}
\hline & \multicolumn{2}{l}{ Tumour size } \\
\cline { 2 - 3 } Observed survival (\%) & $\geqslant 30 \mathrm{~mm}$ & $<30 \mathrm{~mm}$ \\
\hline $0-3$ months & 31 & $7^{\star}$ \\
$3-6$ months & 21 & 10 \\
$>6$ months & $13^{\star}$ & 19 \\
\hline$\star$ Misclassifed patients &
\end{tabular}

${ }^{\star}$ Misclassified patients.

Statistical significance was determined using the $\chi^{2}$ test for qualitative data, and one way analysis of variance and non-parametric tests for quantitative data. Survival times were compared by the log rank test. Survival curves are presented using the actuarial method. The influence of a number of simultaneous variables on survival was estimated with the Cox proportional hazard model. Results are expressed as mean (SD).

\section{Results}

One hundred and five patients were included in the study. Follow up was not available in four patients, three of whom had failed endoprosthesis insertion, and one did not comply with the stent exchanges required. Data from these four patients were therefore not included in the analysis. The patient characteristics of the three groups were similar (table 1). Histological confirmation of malignancy was obtained in $65 \%$ of cases. In all other cases, the patient's history was typical of biliary or pancreatic cancer. Tumour size was obtained from computed tomography or ultrasound scans in 68 patients and from ERCP alone in 33. Four patients were lost at follow up: three had moved from France to another country, and one had been followed in another centre from which no information could be obtained. Three patients underwent surgery during follow up for symptoms of gastric outlet obstruction: one had a gastroenteric bypass 155 days after inclusion and two others had a choledochoduodenal and gastrojejunal anastomosis 22 and 365 days, respectively, after

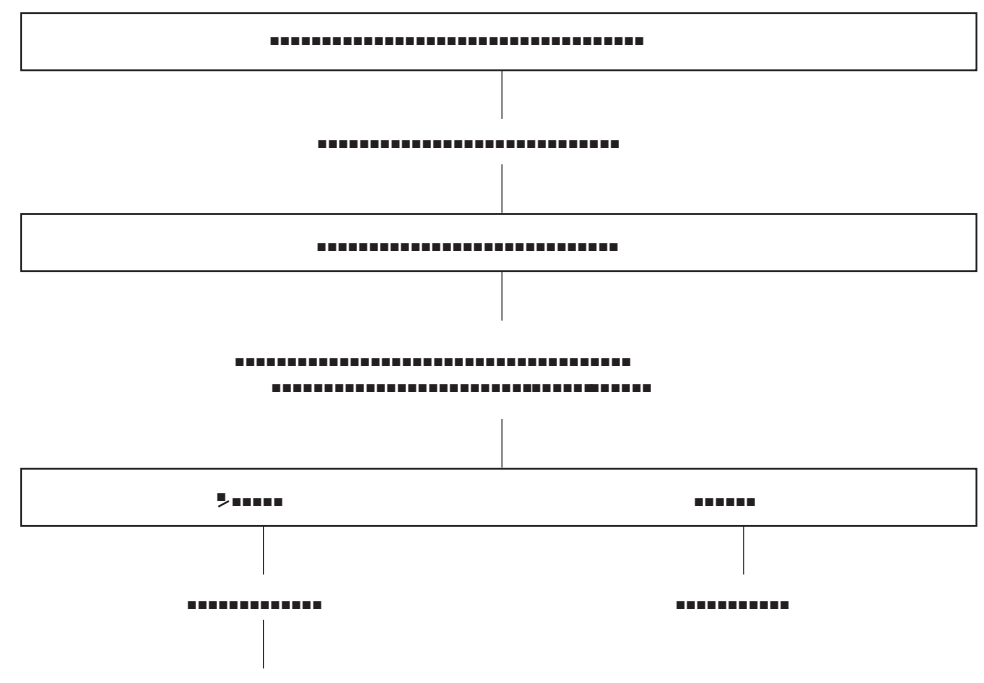

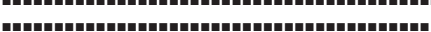

Figure 3 Algorithm for patient management. inclusion. Another patient underwent a hepatojejunal anastomosis 384 days after inclusion for stent dysfunction.

Biliary drainage was successful in $97.4 \%$ of cases. Procedure related morbidity and mortality were $11.9 \%$ and $3.9 \%$, respectively, with no difference between groups; there were six cases of biliary sepsis, two cases of pancreatitis, one bleeding sphincterotomy, and one case of transitory renal failure. Two patients died within eight days of primary stent insertion from biliary sepsis and two others from upper digestive haemorrhage, in which the causative role of endoscopic procedures was suspected, but not proved.

The mean follow up after inclusion was 166 (131) days. By the end of the study, 81 patients $(80.2 \%)$ had died. The global median survival was 143 days (4.7 months). Figure 1 presents the global survival curve; $37.6 \%$ of the patients survived less than three months, $30.7 \%$ three to six months, and $31.7 \%$ more than six months.

In the univariate analysis, only two of the seven items tested were found to be significantly associated with survival: percentage weight loss and tumour size. In the multivariate analysis, tumour size was the only independent predictor of survival (table 2). The study population was split into two samples, depending on tumour size, and survival was compared between these samples by the log rank test. Using this method, a threshold of $30 \mathrm{~mm}$ in size was determined as the best survival discriminator (fig 2): the median survival was 6.6 months for patients with a tumour smaller than $30 \mathrm{~mm}$ and 3.2 months for patients with a larger tumour $(\mathrm{p}<0.001)$.

When applied to the 101 patients included, $19(18.8 \%)$ would have been correctly classified as surviving more than six months, 62 $(61.4 \%)$ correctly classified as surviving six months or less, and $20(19.8 \%)$ would have been wrongly classified (table 3 ).

\section{Discussion}

In our randomised trial, we have shown that self expanding metal stents significantly increased the symptom free survival compared with plastic stents. However, a cost effectiveness analysis had shown that this improvement was really beneficial only for the subgroup of patients surviving more than six months $(32 \%$ in this study). ${ }^{11}$ Predictive factors of survival therefore remained to be determined.

The restoration of efficient biliary drainage has been shown to be useful not only for the relief of jaundice and pruritus, but also to improve the general quality of life, by increasing appetite and reducing indigestion. ${ }^{314}$ In inoperable patients, this objective is all the more important since treatment is purely palliative, aimed at reducing symptoms of discomfort and improving patients' well being for their remaining lifetime. In patients with malignant jaundice, the ideal palliative treatment is therefore a drainage method with a low procedure related morbidity (which is the case with endoscopic stents, as compared with transhepatic stents and bypass surgery ${ }^{4}$ ), and a 
low late morbidity for those with the longest survival (which is the case with bypass surgery, but not with plastic stents). ${ }^{15}{ }^{16}$ Metallic stents appear to meet both end points, with a low probability of symptomatic dysfunction even in long term survivors. ${ }^{17}$ In the few patients who develop stent obstruction, endoprosthesis intubation with a plastic stent remains possible, and in the even fewer patients who develop duodenal obstruction ( $3 \%$ in our series), a simple gastrojejunal anastomosis is not precluded. However, the cost of metallic stents is roughly 15-20-fold higher than that of polyethylene stents, and is not likely to be drastically reduced, due to high manufacturing costs. A cost effective management policy therefore would be to use plastic stents in patients with a short life expectancy (less than six months, according to our data), and metal stents in other patients (expected to survive at least six months).

This study has shown that an assessment of biliopancreatic tumour size is a sufficient predictor of survival. In the univariate analysis, tumour size and weight loss were found to be predictive of survival. In patients with a cancer of the head of the pancreas, $80-90 \%$ present with significant weight loss on diagnosis. ${ }^{18}$ This factor is inconstantly recognised as prognostic. ${ }^{19}$ The weight is not an accurate reflection of the cancer patient's nutritional status, because of the usual expansion of extracellular fluids and oedema. ${ }^{20} \mathrm{~A}$ more accurate evaluation of nutritional status might improve the assessment of prognosis, such as has been shown by Falconer et al with albuminaemia. ${ }^{21}$ Performance status was not tested as a prognostic variable, as all the patients had been selected at inclusion for having a fair performance status. A low performance status is, however, associated with poor prognosis. Several studies omitted to consider the presence of distant metastases as a potential prognostic factor. However, in contrast to our results, van den Bosch et $a l,{ }^{16}$ as well as Pereira-Lima et al in a retrospective study, ${ }^{22}$ have shown that the presence of distant metastases remained a significant predictive factor of poor survival even in a multivariate analysis. However, our patients were referred for palliative treatment because they were considered inoperable; the group had a larger (and therefore statistically less discriminant) percentage of metastatic patients $(28 \%)$ than in surgical series. In our multivariate analysis, tumour diameter was the only independent prognostic factor. Other factors clearly related to survival (such as presence of liver metastases, weight loss, and histology) are indeed linked to tumour size. The size factor has been identified in previous studies. ${ }^{23-27}$ However, these studies presented conflicting results probably because they included either operable patients (those with relatively small tumours) or inoperable patients (generally with larger tumours).

We suggest that endoscopic drainage devices should be selected using an algorithm based on tumour size (fig 3): in a patient presenting for the first time with inoperable malignant jaundice and a tumour smaller than $30 \mathrm{~mm}$ in diameter, the expected median survival is 6.6 months; a metal stent is therefore recommended. On the other hand, patients presenting with a tumour larger than $30 \mathrm{~mm}$ have an expected median survival of 3.2 months, justifying the use of a plastic stent. If this decision algorithm had been used in our series, $7 \%$ of the patients would have unnecessarily received a metal stent, because of their unexpectedly short survival (table 3 ). Whatever the method for calculating the costs per patient, this is much less than the excess cost induced by a systematic use of metal stents in every patient (two thirds of whom do not exceed six months in survival). On the other hand, $13 \%$ with large tumours at the time of diagnosis finally survived more than six months. In such cases, the prognosis can be corrected when more follow up is available, and the plastic stent can be exchanged, either prophylactically or after a symptomatic dysfunction, for a metal stent. This approach would be easy to apply and we believe warrants a prospective controlled study.

1 Gudjonsson B. Cancer of the pancreas: 50 years of surgery. Cancer 1987;60:2284-303.

2 Sarr MG, Cameron JL. Surgical palliation of unresectable carcinoma of the pancreas. World 7 Surg 1984;8:906-18.

3 Cotton PB, Schmidt C. Quality of life in palliative management of malignant obstructive jaundice. Scand $\mathcal{F}$ Gastroenterol 1993;28(suppl):44-6.

4 Speer AG, Cotton PB, Russel RC, et al. Randomised trial of endoscopic versus percutaneous stent insertion in malignant obstructive jaundice. Lancet 1987; ii:57-62.

5 Smith AC, Dowsett JF, Russel RCG, Hatfield AR, Cotton PB. Randomised trial of endoscopic stenting versus PB. Randomised trial of endoscopic stenting versus
surgical by-pass in malignant low bile duct obstruction. Lancet 1994;344:1655-60.

6 Shepherd HA, Royle G, Ross AP, Diba A, Arthur M, ColinJones D. Endoscopic biliary endoprosthesis in the palliation of malignant obstruction of the distal common bile duct: a randomized trial. Br F Surg 1988;75:1166-8.

7 Andersen JR, Sörensen SM, Kruse A, Rokkjaer M, Matsen $P$. Randomised trial of endoscopic endoprosthesis versus operative bypass in malignant obstructive jaundice. Gut 1989;30:1132-5.

8 Davids PHP, Groen AK, Rauws EAJ, Tytgat GNJ, Huibregtse K. Randomised trial of self-expanding metal stents versus polyethylene stents for distal malignant biliary obstruction. Lancet 1992;340:1488-92.

9 Knyrim K, Wagner HJ, Pausch J, Vabil N. A prospective randomized controlled trial of metal stents for malignant obstruction of the common bile duct. Endoscopy 1993;25: 207-12.

10 Cotton PB. Metallic mesh stents. Is the expanse worth the expense? Endoscopy 1992;24:421-3.

11 Prat F, Chapat O, Ponchon T, et al. Endoscopic palliation of malignant biliary strictures: results of a prospective randomized study [abstract]. Endoscopy 1996;28:S37.

12 Eastern Cooperative Oncology Group. In: WHO handbook for reporting results of cancer treatment. Geneva: World Health Organisation, 1979.

13 Keats AS. The ASA classification of physical status. A recapitulation. Anesthesiology 1978;49:233-6.

14 Ballinger AB, McHugh M, Catnach SM, Alstead EM, Clark ML. Symptom relief and quality of life after stenting for malignant bile duct obstruction. Gut 1994;35:467-70.

15 Buffet C, Couderc T, Fritsch J, et al. Traitement palliatif par endoprothèse des ictères par obstacle tumoral sous-hilaire. Gastroenterol Clin Biol 1993;17:629-35.

16 van den Bosch RP, van der Schelling GP, Klinkenbijl JHG, Mulder PG, van Blankenstein M, Jeekel J. Guidelines for the application of surgery and endoprostheses in the palliation of obstructive jaundice in advanced cancer of the pancreas. Ann Surg 1994;219:18-24.

7 O'Brien S, Hatfield ARW, Craig PI, Williams SP. A three-year follow-up of self-expanding metal stents in the endoscopic palliation of long term survivors with malignant biliary obstruction. Gut 1995;36:618-21.

18 De Wys WD. Weight loss and nutritional abnormalities in cancer patients: incidence, severity and significance. In: Calman KC, Fearon KC, eds. Nutritional support for the cancer patient. London: Balliere Tindall, 1986:251-61.

19 Mannell A, Weiland LH, Van Heerden JA, Ilstrup DM. Factors influencing survival after resection for ductal adenotors influencing survival after resection for ductal adeno
carcinoma of the pancreas. Ann Surg 1986;203:403-7.

20 Fearon KC, Preston T. Body composition in cancer cachexia. Infusion Therapy 1990;17(suppl 3):63-6. 
21 Falconer JS, Fearon KC, Ross JA, et al. Acute-phase protein response and survival duration of patients with pancreatic response and survival duration of

22 Pereira-Lima LC, Jakobs R, Maier M, Benz C, Kohler B, Riemann JF. Endoscopic biliary stenting for the palliation of pancreatic cancer: results, survival predictive factors, and comparison of 10-French with 11.5-French gauge stents. Am $\mathcal{F}$ Gastroenterol 1996;91:2179-84.

23 Nix GA, Dubbelman C, Wilson JH, Schütte HE, Jeekel J, Postema RR. Prognostic implications of the tumour diameter in carcinoma of the head of the pancreas. Cancer 1991; 67:529-35.
24 Tsuchiya R, Oribe T, Noda T. Size of the tumour and other factors influencing prognosis of carcinoma of the head of

25 Petrek JA, Sandberg WA, Bean PK, Bradley EL. Can Petrek JA, Sandberg WA, Bean PK, Bradley EL. Can
survival in pancreatic carcinoma be predicted by primary size or stage? Am Surg 1985;51:42-51.

26 Tsuchiya R, Noda T, Harada N, et al. Collective review of small carcinomas of the pancreas. Ann Surg 1986;203: $77-81$.

27 Fortner JG, Klimstra DS, Senie RT, Maclean BJ. Tumour size is the primary prognostic indicator for pancreatic cancer after regional pancreatectomy. Ann Surg 1996;223:147-53.

\section{Gut-http://www.gutjnl.com}

Visitors to the world wide web can now access Gut either through the BMJ Publishing Group's home page (http://www.bmjpg.com) or directly by using its individual URL (http://www.gutjnl.com). There they will find the following:

- Current contents list for the journal

- Contents lists of previous issues

- Members of the editorial board

- Subscribers' information

- Instructions for authors

- Details of reprint services.

A hotlink gives access to:

- BMJ Publishing Group home page

- British Medical Association web site

- Online books catalogue

- BMJ Publishing Group books

The web site is at a preliminary stage and there are plans to develop it into a more sophisticated site. Suggestions from visitors about features they would like to see are welcomed. They can be left via the opening page of the BMJ Publishing Group site or, alternatively, via the journal page, through "about this site". 